Article

\title{
Analysis of EEG, Cardiac Activity Status, and Thermal Comfort According to the Type of Cooling Seat during Rest in Indoor Temperature
}

\author{
Yunchan Shin, Minjung Lee and Honghyun Cho*
}

Citation: Shin, Y.; Lee, M.; Cho, H. Analysis of EEG, Cardiac Activity Status, and Thermal Comfort According to the Type of Cooling Seat during Rest in Indoor Temperature. Appl. Sci. 2021, 11, 97. https://dx.doi. org/10.3390/app11010097

Received: 28 November 2020 Accepted: 22 December 2020 Published: 24 December 2020

Publisher's Note: MDPI stays neutral with regard to jurisdictional claims in published maps and institutional affiliations.

Copyright: (C) 2020 by the authors. Licensee MDPI, Basel, Switzerland. This article is an open access article distributed under the terms and conditions of the Creative Commons Attribution (CC BY) license (https: / / creativecommons.org / licenses/by/4.0/).
Department of Mechanical Engineering, Graduate School of Chosun University, 303 Pilmun-daero, Dong-gu, Gwangju 501-759, Korea; sinyc17@chosun.kr (Y.S.); jung612@chosun.kr (M.L.)

* Correspondence: hhcho@chosun.ac.kr; Tel.: +82-62-230-7050; Fax: +82-62-230-7055

\begin{abstract}
In this study, electroencephalogram (EEG) and cardiac activity status of the human body while using various types of seats during rest were analyzed in indoor summer conditions. Thermal comfort was also evaluated through a subjective survey. The EEG, cardiac activity status, and subjective survey during rest indicated that the use of ventilation and cold water-cooling seats was effective. This effectiveness was because of the $\theta$-wave and $\alpha$-wave activation, sensorimotor rhythm, $\beta$-wave reduction, and left hemisphere activation, demonstrating that the conditions applied were suitable for rest. According to the analysis of the subjective questionnaire survey, the use of ventilation and cold water-cooling seats provided a more pleasant state than the basic seat, improving the subject's warmth and comfort, and also the concentration. In addition, the use of a cold water-cooling seat provided the highest satisfaction level, being the most favorable condition for rest.
\end{abstract}

Keywords: electroencephalogram (EEG); electrocardiogram (ECG); photoplethysmography (PPG); thermal comfort; cardiac activity status

\section{Introduction}

In modern society, current developments lead to significant and fast changes. This rapid growth requires effective use of time, which is a key factor in achieving personal goals. Adequate rest for short periods can also assist in the efficient use of time. If humans do not take adequate rest while working, they cannot relieve stress. This workload can deteriorate the adrenal functions and cause the release of scant or excessive levels of cortisol, known as the stress hormone [1]. Thus, it results in chronic fatigue, depression, helplessness, decreased concentration, decreased memory, syndrome before menstruation, muscle pain, sleep disorders, gastrointestinal disorders, eating disorders, and infertility. Therefore, short but adequate and physiological rest is necessary during the current rapid changes in modern society. People can calm the body and mind and remove the stress accumulated in the body through a variety of relaxation methods, including various recreational activities. In addition, it is essential to prevent multiple symptoms that can be caused by stress and to maintain body and mind elasticity to maintain the hormone balance in the body [2]. Physiologically sufficient rest restores the function of the adrenal gland and restores the balance in stress hormones [3]. Therefore, it is essential to maintain human performance, manage fatigue, and reduce the accumulation of risks in a lengthy task.

Various studies on thermal comfort of humans during rest have been conducted. However, most of them are focused on improving the thermal environment in extreme environmental conditions or are subjective surveys based on various thermal ecological factors. However, in the case of subjective surveys, as they are differently evaluated according to the individual's sensitivity for a given temperature, and reaction uncertainty 
is very high, it is necessary to analyze the situation through measurement of various objective indicators and to study their comprehensive relationship.

Generally, it is possible to verify the heart rate variability metrics, such as lowfrequency (LF) and high-frequency (HF) activities, standard deviation of N-N interval (SDNN), and root mean square of the successive differences (RMSSD) through cardiac activity. LF components, which indicate sympathetic nerves, appear high in tension or excitement states, whereas HF components, which indicate parasympathetic nerves, appear low in anger, anxiety, and fear states. A standard pulse deviation, SDNN is a measure of external environmental adaptability. When it is high, it indicates a better adaptability to the given environment. In addition, low values of RMSSD are obtained when feeling anger, anxiety, and fear. In previous studies, Byeon et al. [4] and Liu et al. [5] reported that electrocardiogram (ECG) signals could be obtained by detecting and amplifying microscopic electrical signals on the skin using non-invasive electrodes. In addition, the effects of temperature and ambient light on the pulse waves were investigated, and they reported that peripheral blood vessels in cold weather caused vascular contraction and abnormal blood flow as a potential method for clinical diagnosis. In addition, Lee et al. [6] investigated the correlation between ECG and photoplethysmography (PPG) data. They reported that a PPG sensor can replace the sleep state detection of drivers using ECG data, and will potentially be more economical.

Electroencephalogram (EEG) signals are a type of biosignal of the human body that can be measured by non-invasively fixing flat electrodes in specific areas of the scalp, using a conductive adhesive, and measuring the potential difference between them. Brain waves are caused by synchronic electrical waves generated by cerebral cortical neurons transmitting signals among each other [7]. The synaptic current in the dendrites is the current induced in the process of communication among cortical neurons located directly under the skull. The measurement of human EEG is relatively economical and can provide considerable information regarding brain function in a short period of examination. In addition, there is no risk of exposure to radioactivity; thus, related research has been actively conducted under various environments and conditions. Representative studies related to human EEG measurement have mainly focused on evaluating changes in EEG caused by direct/indirect stimulation. Choi et al. [8] examined the changes in EEGs according to the level of stress caused by indirect stimulation with changes in the indoor environment. From the physiological perspective, the subject's stress was maximized when the temperature was $30^{\circ} \mathrm{C}$ and when they were exposed to odor stimulant volatile organic compounds and road traffic noise. Zhang et al. [9] studied variations in EEG and heart rate (HR) of subjects according to indoor temperature in summer. At a temperature of $25^{\circ} \mathrm{C}$, the subject's cognitive load was significantly reduced; however, the EEG and HR function did not significantly change. Vesseler and Zeiler [10] conducted a study on local heating by directly supplying the heat to the body in public and commercial buildings, and they confirmed that local ventilation and heating increased energy savings in the building industry and the thermal comfort of the occupants. Besides, many similar studies reported that local cooling on the face, arm, thighs, and upper body in the hot condition could improve the thermal comfort of the occupants [11-14]. Veselý et al. [15] reported that local heating, using heated chairs, desk mats, and floor mats, could considerably improve thermal comfort by individually controlling the temperature of subjects. Zhu et al. [16] observed that changes in the EEG signal occurred upon increasing the indoor temperature and relative humidity. Based on this result, they reported that research on the feasibility and usefulness of EEG was needed to investigate the effect of the indoor environment on human cognitive performance. Shan et al. $[17,18]$ experimentally studied a new method based on EEG to enhance human-object interaction under various room temperature conditions and classified the real-time thermal comfort status of occupants through an EEG-based machine learning method. They reported that the left-right asymmetry score was approximately zero in cool and warm conditions for the rest condition, and the setting of a comfortable condition could achieve building energy savings. 
In addition, Chang et al. [19] examined the EEG effect on painless heat and cold stimulation by studying EEG changes on direct stimulation, such as thermal stimulation. The experimental results showed a significant decrease in $\theta$-wave activity in the frontal lobe during cold stimulation rather than painless thermal stimulation. Chang et al. [20] also investigated the relationship between the dynamics of EEG activation and changes in pain level through a cold pressure test. Their result showed that the $\delta$-wave, $\theta$-wave, and $\beta$ wave activities increased during the cold pressure experiment, whereas the $\alpha$-wave activity decreased. This phenomenon is expected to contribute to the treatment of pain and stress in humans. Besides, Shan et al. [21] examined the EEG response to tonic cold pain. The experimental results indicated a significant negative relationship between EEG activation and subjective pain rating. The brain's perception of tonic cold pain has emerged as a change in cortical source power across different frequency bands in various brain regions.

Many studies have been conducted on changes in biosignals under various environmental conditions. As a representative study of EEG analysis during driving, Shin et al. [22] measured the EEGs and pulses of the subject when the indoor temperature of the vehicle changed from an unpleasant to a pleasant environment by using a driving simulation. In addition, they reported that the $\alpha$-wave frequencies increased and stress sensitivity decreased in the environment in which the subjects felt comfortable. Moreover, Diaz-Piedra et al. [23] evaluated EEG activity according to the complexity of the terrain during driving by using a driving simulation. They reported that the driver's condition could be continuously monitored by the changes in EEGs to immediately detect overload/unload and provide feedback to the driver to take countermeasures and prevent fatal errors. Yang et al. [24] developed a short-term driving condition prediction model by studying the characteristics of the driver's EEGs, assuming the cause of traffic accidents and estimating the driving condition. In addition, Jiao et al. [25] identified the level of drowsiness by examining the driver's EEGs and proposed a new model for detecting driver drowsiness. An average accuracy of $98 \%$ was achieved by verifying and classifying drowsiness in drivers by tracking the changes in the $\alpha$-wave activity and extracting shapes from physiological signals. Furthermore, Jing et al. [26] studied the driver fatigue state in a low-voltage and low-oxygen environment to monitor psychological parameters through EEG measurements. They provided basic data on the theory and inspection for the design of the driving fatigue-warning device and their result was considerably significant to the development of a driver's fatigue detection system. In addition, concentration and thermal comfort of subjects were investigated by using subjective questionnaires and measurement of biosignals in various indoor environments [27]. They reported that the stress was low in an appropriate indoor environment, and the concentration was increased as activity of the alpha wave increased. Besides, LF/HF decreased, and SDNN and RMSSD increased, under a comfortable environment.

Various studies have been conducted on biosignals in humans in rest conditions. Long et al. [28] examined the effect of music on EEGs during sleep. During one week, the subjects listened to music for $30 \mathrm{~min}$ before sleep. As a result, the spectral density increased in the LF range $(0-3 \mathrm{~Hz})$, whereas it decreased in the $\mathrm{HF}$ range, of more than $12 \mathrm{~Hz}$, after listening to music. Therefore, they concluded that the quality of sleep was improved when music was used. Lan et al. [29] investigated the effect of indoor temperature on the sleep quality and the thermal comfort of subjects. EEG analysis showed that it takes longer for the subject to fall asleep at an environment temperature of $30^{\circ} \mathrm{C}$ than at $26^{\circ} \mathrm{C}$. Moreover, they reported that the duration of the slow-wave sleep was shorter when the room temperature was outside the neutral range. In addition, various experiments related to EEG analysis in resting condition were also conducted. Barry and De Blasio [30] analyzed eyes open and closed during rest to examine the difference in EEG responses between young and older people. Their results indicated that elderly maintained the responsiveness of the energy system, compared to young people, and maintained their perception and cognitive abilities by utilizing additional focus brain activity in the resting condition. Massar et al. [31] and Pitchford and Arnell [32] confirmed that the $\theta$-wave activity in the rest state was related 
to reinforcement learning, and the difference in compensation sensitivity explained this relationship. Additionally, Joshi et al. [33] and Zhu et al. [34] reported that the environment affected human sleep and awakening, which affected the body's thermal rhythm. They also mentioned that it is necessary to analyze the thermal comfort through appropriate control of the ambient and skin surface temperatures.

Several studies have been conducted on the relationship between the thermal comfort of the human body under various environments. However, most of the existing thermal comfort analyses use subjective surveys and single emotional signal analysis, and only few researches focus on the relationship of various biosignals. In addition, most studies on the evaluation of thermal comfort apply outdoor temperatures during summer and winter, which are almost extreme conditions. However, limited research has been conducted on resting in an indoor condition, where people usually work or study. Therefore, it is necessary to conduct a study on variations in the biosignals of the human body in an environment at $27.5^{\circ} \mathrm{C}$, which is considered as a typical indoor temperature during summer. Furthermore, most of the existing studies on thermal comfort were conducted during office work, driving, exercise, and sleep, and no EEG studies have been conducted on short-term rest to improve the quality of rest. In this study, EEG and cardiac activity status of the human body were analyzed according to changes in various seats during short rests in summer indoor conditions, and changes in concentration and thermal sensitivity were also evaluated. This study can provide basic data on the characteristics of short-term rest conditions, information on the improvement of the quality of rest, and the relationship between biosignals and attention.

\section{Experimental Setup and Methods}

In this study, an experimental device was designed to conduct an experimental study on the subject's thermal comfort when they taking a break by applying various seats under indoor condition in summer. Analysis of EEG, cardiac activity status, and subjective questionnaires of the subject during rest were performed using the experimental setup.

\subsection{Experimental Setup}

The subjects disposed of electronic equipment and metal accessories before EEG measurement. The subjects wore an EEG cap, and the EEG was measured only when the electrode-skin impedance showed a value of $100 \mathrm{k} \Omega$ or more, which was assumed as a stable condition. After EEG measurement, EEGs were analyzed using the TeleScan program and visualized through three-dimensional brain mapping. In this study, the summer indoor rest condition was set based on the resting state during work, and the experiment was performed under clothing conditions, with short sleeves, long pants, underwear, and socks.

To measure the subjects' EEGs during resting indoors, the EEG device (QEEG-64FX, Laxtha, Korea) was directly connected with the subject's head. This is a high-precision multi-channel wide band biometric system with a three channels bipolar, and it can measure the biosignal by applying HPF, LPF, and Notch filters according to the target signal. The EEG measuring equipment used A2 as the reference electrode, and 16 channels were installed on the subject's head, as shown in Figure 1. In general, both the left and right reference electrodes can be used, but, in some cases, the ECG signal can be mixed with some EEG signals when it is used at the left side. Therefore, the right earlobe (A2) was attached as the reference electrode in this study. The head was primarily divided into four parts to analyze the variation of EEG at different parts of the head, as shown in Table 1. In Figure 1, the frontal lobe zone is composed of prefrontal (Fp1, Fp2), left frontal (F3, F7), and right frontal lobes (F4, F8); the central lobe zone has the parietal (C3, C4, P3, P4), left parietal (P7), and right parietal lobes (P8). In addition, the temporal lobe zone has the left (T7) and right temporal lobes (T8), and the occipital lobe zone has the occipital lobes (O1 and O2). The uBio Macpa device, with a measurement range of 40-200 beats per minute (BPM) and a measurement error of $\pm 2 \%$, was also used to measure cardiac activity status. 


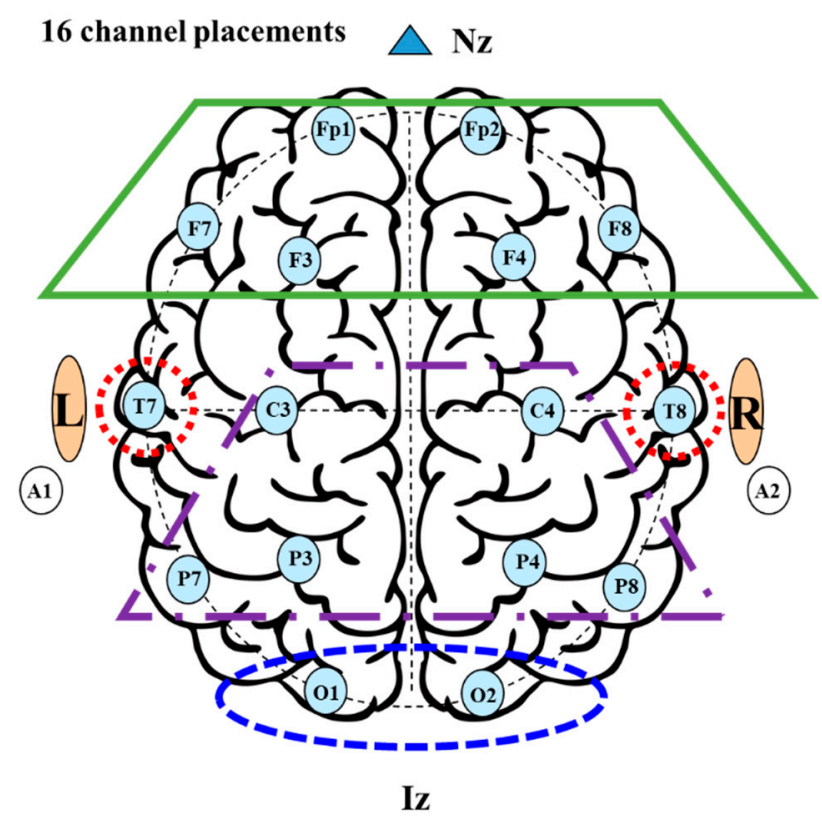

Figure 1. Electrode positions and lobes at the 16-channel system.

Table 1. Electrode position and lobes for the 16-channel system.

\begin{tabular}{cc}
\hline Item & Specification \\
\hline Frontal lobe zone & Fp1, Fp2, F3, F4, F7, F8 \\
Central lobe zone & C3, C4, P3, P4, P7, P8 \\
Temporal lobe zone & T7, T8 \\
Occipital lobe zone & O1, O2 \\
\hline
\end{tabular}

The EEG data was collected using the TeleScan program which was provided by LAXTHA. This program controlled the computerized equipment from the computer side with equipment control, real-time data collection, and time series analysis software, and measured/stored/analyzed in real time. In addition, BrainMap-Addon EEG analysis and $3 \mathrm{D}$ brain mapping program were used to analysis of EEG frequency. By these programs, brain mapping visualization, power, and correlation analysis of EEG analysis results were performed. Cardiac activity status was measured by photoelectric pulse wave method. This method is to measure the change of light that passes through the body by irradiating infrared rays and red light on the surface of the human body in order to measure the change in blood flow that changes according to the pulsation of the heart

In this study, three different seats were employed under indoor rest conditions in summer: a basic seat, which is a general office chair, a ventilation seat, in which indoor air circulates, and a cold water-cooling seat, in which $4{ }^{\circ} \mathrm{C}$ cold water flows using a constant temperature bath. Figure 2 shows a photograph of seat temperatures using a thermal imaging camera when the ventilation and cold water-cooling seats are applied under an indoor temperature of $27.5^{\circ} \mathrm{C}$ in summer. The measuring range of the thermal imaging camera used in this study is $-20-120^{\circ} \mathrm{C}$, and its thermal sensitivity is $<40 \mathrm{mK} @ \mathrm{f} / 1.0$, $30 \mathrm{~Hz}$, and $300 \mathrm{~K}$. Applying the cold water-cooling seat for $5 \mathrm{~min}$, the temperature of the seat decreased by $5.7^{\circ} \mathrm{C}$. In general, ventilation seats are widely used in automobiles. In the ventilation seat, air inflows at the bottom by the fan motor and is discharged through 50 wind-holes, directly flowing to the subject's body. This can increase the drying of sweat and rotation of air. Therefore, it improves the control of the body temperature and improves thermal comfort. In the cold water-cooling seat in summer, the inlet temperature of cold water is set at $4{ }^{\circ} \mathrm{C}$ with a flow rate of $0.1 \mathrm{~kg} / \mathrm{s}$ by using a $1 \mathrm{~cm}$ diameter urethane tube in the seat, and the constant temperature bath controls the temperature. The temperature of the cold water supplied from the constant temperature bath to the cold water-cooling 
seat was set to $5^{\circ} \mathrm{C}$, but a cushioning and insulating material were used inside the seat to maintain the temperature. As shown in Figure 2, the temperature between the subject and the resting seat was an average of $15^{\circ} \mathrm{C}$, thus it could be proper for the subject's rest. By using this seat, it is possible to actively reduce the heat generation from the subject's body and effectively reduce the body temperature by direct contact with the cold seat.

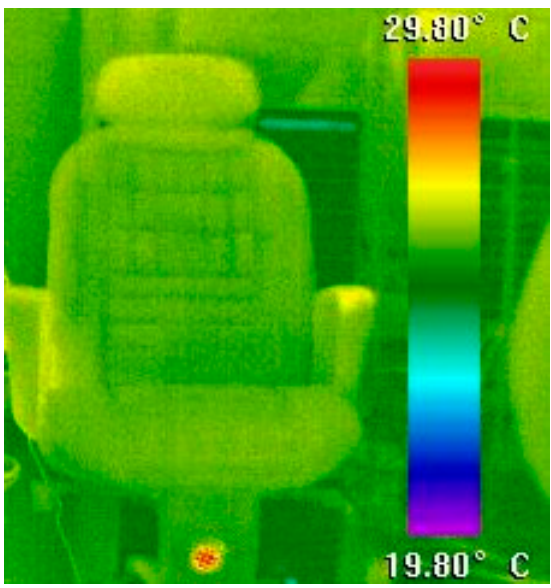

(a)

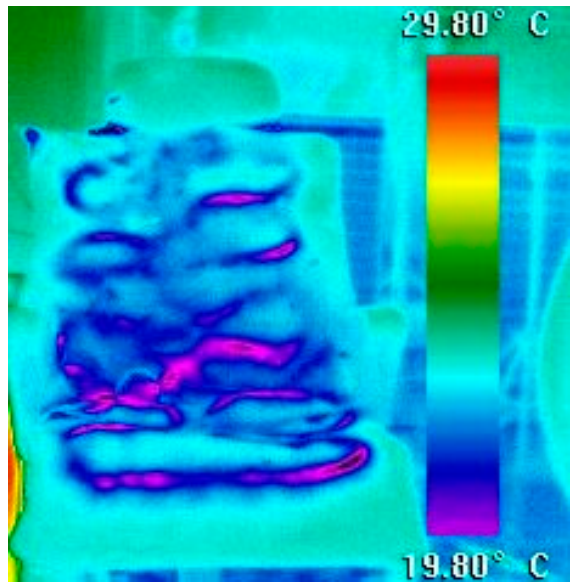

(b)

Figure 2. Infrared camera pictures of various cooling seats. (a) $\mathrm{T}_{\mathrm{a}}=27.5^{\circ} \mathrm{C} /$ ventilation cooling seat. (b) $\mathrm{T}_{\mathrm{a}}=27.5^{\circ} \mathrm{C} /$ cold water-cooling seat.

\subsection{Subject Condition}

In this study, 20 healthy adults were recruited, from which 10 with no history of attention deficit disorder, alcohol or caffeine addiction, or mental illness were selected. The selected subjects were guided regarding the recommended procedures of the activities to be executed one week before the experiment. Pretraining was conducted two days before the experiment, to explain the experiment process and method in detail. In addition, at least $8 \mathrm{~h}$ of sleep were recommended, and substances such as alcohol, tobacco, and caffeine were restricted one day before the test. The average age and physical condition of the 10 subjects of this study are shown in Table 2. Six males and four females with an average age of $27 \pm 3.0$, and average height and weight of $63.3 \pm 16.6 \mathrm{~kg}$ and $179.3 \pm 6.2 \mathrm{~cm}$, respectively, participated in this experiment. The indoor temperature was set to $27.5^{\circ} \mathrm{C}$ based on the rest condition during work indoors in summer, and the amount of clothing was set to 0.35 clo, referring to short sleeves, long pants, underwear, and socks. The subject's metabolic rate was assumed to be approximately $1.8 \mathrm{met}$, because the subjects only answered a simple questionnaire and rested.

Table 2. Anthropometry data of the subjects.

\begin{tabular}{cc}
\hline Item & Specification \\
\hline Gender & 6 males, 4 females \\
Age & $27 \pm 3.0$ \\
Weight & $63.3 \pm 16.6 \mathrm{~kg}$ \\
Height & $179.3 \pm 6.2 \mathrm{~cm}$ \\
Amount of clothing & $0.35 \mathrm{clo}$ \\
Metabolism & $1.8 \mathrm{met}$ \\
\hline
\end{tabular}

\subsection{Experimental Method}

In this study, the basic, ventilation, and cold water-cooling seats were applied for indoor rest condition in summer. Figure 3 shows the experimental process and timetable. First, after EEG and cardiac activity status measuring equipment were attached to the subjects, they followed on to the preparation room at a temperature of $25^{\circ} \mathrm{C}$ and stayed for 
$20 \mathrm{~min}$ to adapt to the indoor condition in summer. In sequence, experiment on biosignal changes was conducted in the test room at a temperature of $27.5^{\circ} \mathrm{C}$ for $20 \mathrm{~min}$. After a 20-min rest on the test seat, simple voting and attention-focused tests were conducted, as shown in Table 3 . After the first experiment, the subjects stayed in the waiting room $\left(25^{\circ} \mathrm{C}\right)$ for $40 \mathrm{~min}$ of free activity. Then, they remained for $20 \mathrm{~min}$ in the preparation room at $25^{\circ} \mathrm{C}$ to adapt to the indoor condition. Subsequently, the ventilation seat was applied in the test room $\left(27.5^{\circ} \mathrm{C}\right)$ and simple voting and attention concentration test was conducted for $5 \mathrm{~min}$ after a $20 \mathrm{~min}$ break. For the cold water-cooling seat, the same procedure was applied. Table 3 shows a questionnaire of seven thermal comfort points used in this study.

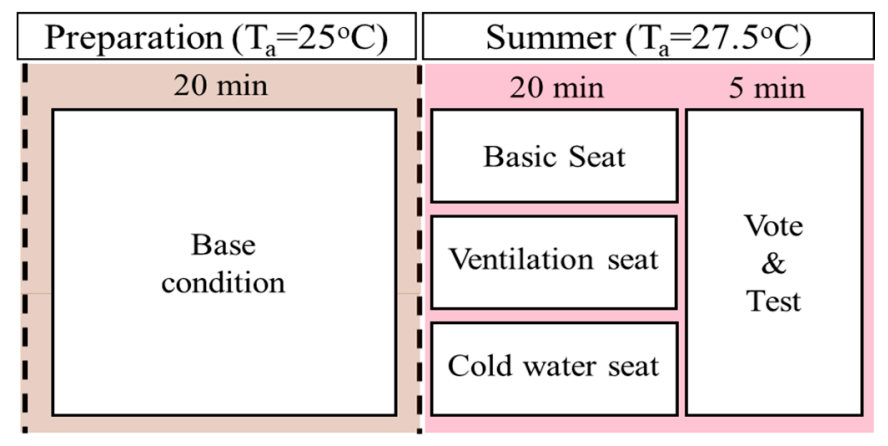

Figure 3. Experimental process and timetable.

Table 3. Thermal sensation vote (TSV), comfort sensation vote (CSV), and concentration level vote (CLV) questionnaire scales.

\begin{tabular}{|c|c|c|c|}
\hline Vote & $\begin{array}{c}\text { Thermal Sensation Vote } \\
\text { (TSV) }\end{array}$ & $\begin{array}{c}\text { Comfort Sensation Vote } \\
\text { (CSV) }\end{array}$ & $\begin{array}{c}\text { Concentration Level Vote } \\
\text { (CLV) }\end{array}$ \\
\hline+3 & Hot & Very comfortable & Very good \\
\hline+2 & Warm & Comfortable & Good \\
\hline+1 & Slightly Warm & Slightly comfortable & Slightly good \\
\hline 0 & Neutral & Neutral & Neutral \\
\hline-1 & Slightly Cool & Slightly uncomfortable & Slightly bad \\
\hline-2 & Cool & Uncomfortable & Bad \\
\hline-3 & Cold & Very uncomfortable & Very bad \\
\hline
\end{tabular}

\section{Results and Discussion}

In this study, thermal comfort was evaluated by analyzing EEG, heart rate activity status, and subjective questionnaire according to the type of resting seats (basic, ventilation, cold water-cooling seat) under common indoor condition in summer. The thermal comfort from the analysis result of EEG and heart rate were firstly presented, and then the results of comparative analysis on thermal comfort by subjective questionnaires were presented.

\subsection{Analysis of EEG and Cardiac Activity Status in the Cooling Condition}

Figure 4 shows the average frequency of the subjects' frontal lobe zone (Fz), central lobe zone $(\mathrm{Cz})$, temporal lobe zone $(\mathrm{Tz})$, and occipital lobe zone $(\mathrm{Oz})$ during rest using the basic, ventilation, and cold water-cooling seats at $27.5^{\circ} \mathrm{C}$. The $\delta$-wave $(1-3 \mathrm{~Hz})$ and $\theta$-wave (4-7 Hz) components corresponding to $0-7 \mathrm{~Hz}$ were relatively activated in the frontal and occipital lobes. Moreover, it was confirmed that the average frequency was most activated when the cold water-cooling seat was used. An increase in the $\delta$-wave activity in the frontal lobe zone, related to the mood control, and the posterior cortex, associated with signal processing was observed. The increase in the $\delta$-wave activity indicated that the subject felt comfortable during rest using various seats, similar to the brain activity when the human is in a deep sleep. As $\delta$-wave and $\theta$-wave frequencies occur during sleep and drowsiness, it can be inferred that the use of the cold water-cooling seat provided an appropriate sleep and drowsiness environment to the subject during rest. The lowest values in the 
average frequencies of the brain were found in the sensorimotor rhythm (SMR) $(12-15 \mathrm{~Hz})$ and mid $\beta$-wave components $(16-18 \mathrm{~Hz})$ corresponding to $10-20 \mathrm{~Hz}$ in all areas. When the subject was resting, low values of SMR and mid $\beta$-wave average frequencies were obtained because these frequencies occur when the brain maintains concentration in an active state with positive thinking. After an intermediate frequency of $20 \mathrm{~Hz}$, the average frequency of the brain gradually increased at high $\beta$-wave frequencies $(20-30 \mathrm{~Hz})$ and then slightly decreased at the $\gamma$-wave frequencies $(31-50 \mathrm{~Hz}$ ). In this study, the subject conducted a simple concentration test, such as performing office work before and after a break. Subsequently, because the subject sat in a chair and rested for a certain period, the stress caused by the subject's office work affected the variation of brain activity. In all areas, the $\gamma$-wave activity of the ventilation and cold water-cooling seats decreased by $33.3 \%$ and $42.8 \%$, respectively, compared to that of the basic seat. As a result of the experiment, the $\delta$-wave frequencies, which are activated when taking proper rest, were most active when the cold water-cooling seat was used. The $\theta$-wave frequencies, which commonly occur during sleep and drowsiness, were most active when the ventilation seat was used. However, the difference in the $\theta$-wave frequencies between the cold water-cooling and ventilation seat in the temporal and occipital lobes areas was approximately $8 \%$, which is significant. Therefore, the use of a cold water-cooling seat can provide a pleasant resting environment for the subjects.

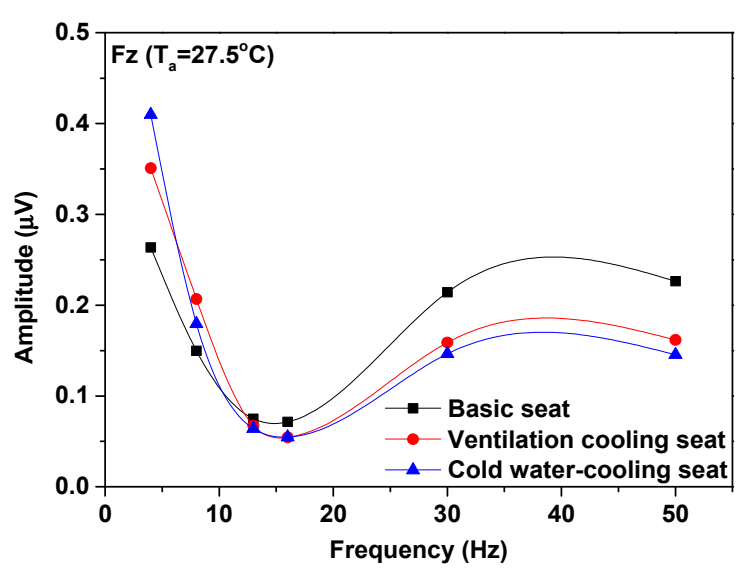

(a) Frontal lobe zone

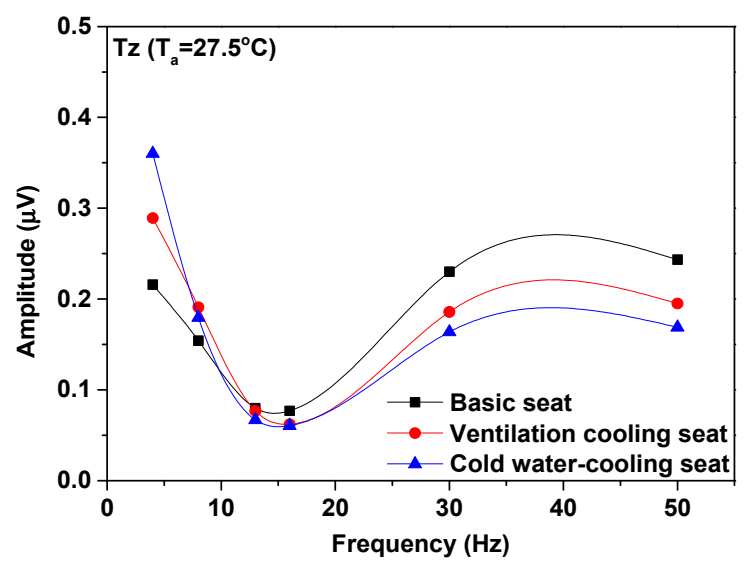

(c) Temporal lobe zone

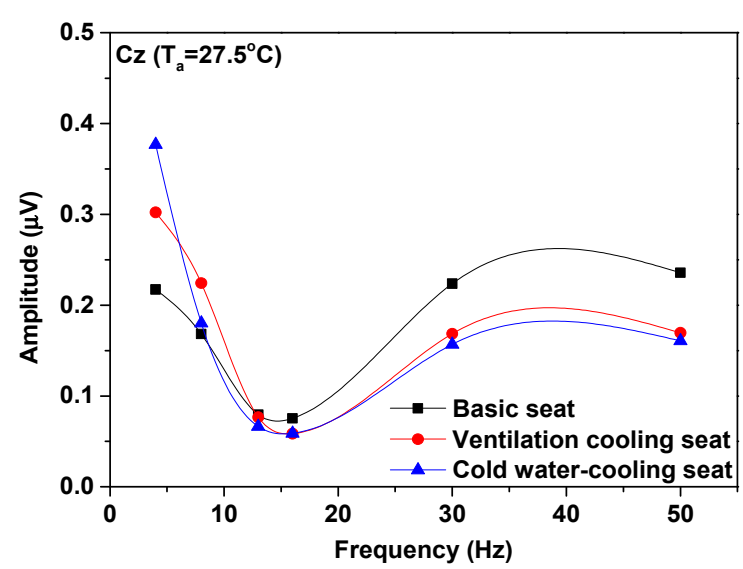

(b) Central lobe zone

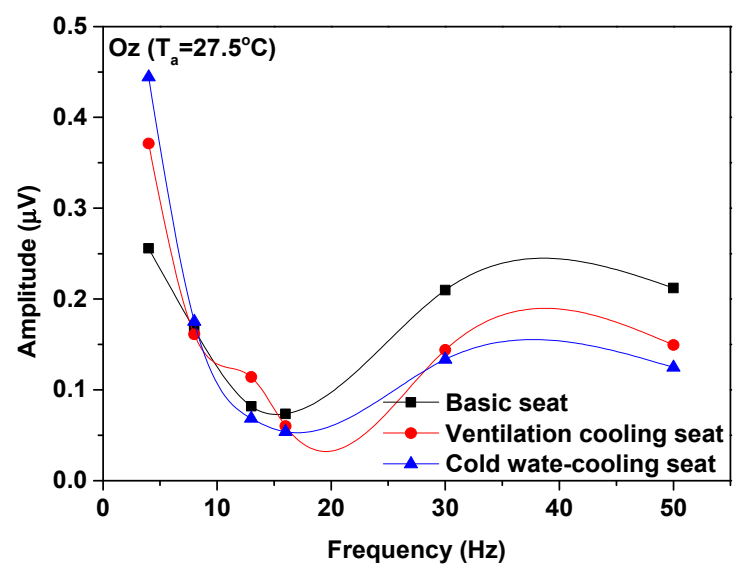

(d) Occipital lobe zone

Figure 4. Averaged frequency spectrum over 16 channels with absolute frequency. (a) Frontal lobe zone (Fz). (b) Central lobe zone (Cz). (c) Temporal lobe zone (Tz). (d) Occipital lobe zone (Oz).

Figure 5 presents a graph of the relative activity ratio of brain waves in the entire brain area when resting, using the basic, ventilation, and cold water-cooling seats at an indoor temperature of $27.5^{\circ} \mathrm{C}$ during summer. Activation of $\theta$-wave means that the subject is 
taking adequate rest, and the activation of SMR and $\beta$-wave increases when the subject is performing concentrated tasks. Activated relative $\theta$-waves represented $23.9 \%, 32.7 \%$, and $39.6 \%$ among brain waves when using basic, ventilation, and cold water-cooling seats, respectively. Therefore, it was confirmed that the relative $\theta$-wave is the most activated among various brain waves. In the case of using the ventilation and cold water-cooling seats, the relative $\theta$-wave increased by $36.8 \%$ and $65.5 \%$, respectively, compared to that when using the basic seat. The proportion of the relative $\alpha$-wave among brain waves was $15.9 \%, 20.5 \%$, and $17.9 \%$, when the basic, ventilation, and cold water-cooling seats were used, respectively. Moreover, when the ventilation and cold water-cooling seats were used, the relative $\alpha$-wave increased by $28.9 \%$ and $12.5 \%$, respectively, compared to that of the basic seat. When using the basic seat, the degree of EEG activation decreased in the following order: relative $\theta$-wave, relative $\gamma$-wave, relative high $\beta$-wave, relative $\alpha$-wave, relative SMR, and relative $\beta$-wave. In the case of using the ventilation and cold watercooling seats, the following order was observed: relative $\theta$-wave, relative $\alpha$-wave, relative $\gamma$-wave, relative high $\beta$-wave, relative SMR, and relative $\beta$-wave. The relative SMR and relative $\beta$-wave are activated when maintaining concentration while learning or thinking, and showed the lowest activity during rest in this study. When the ventilation and the cold water-cooling seats were used, the activation of the relative $\alpha$-wave was different from that using the basic seat. This indirectly indicates that the subject felt more comfortable during the rest and the external concentration was reduced in this state, compared to the case when the basic seat was used. In other words, ventilation and cold water-cooling seats provided a more comfortable rest, compared to the basic seat, in summer indoor spaces. Overall, the relative $\theta$-wave, which is an indicator of sleeping and comfortable rest, was considerably activated, reaching a level of $39.6 \%$ when using the cold water-cooling seat. Therefore, the use of a cold water-cooling seat for resting was the most appropriate method to provide a suitable rest environment for the subjects.

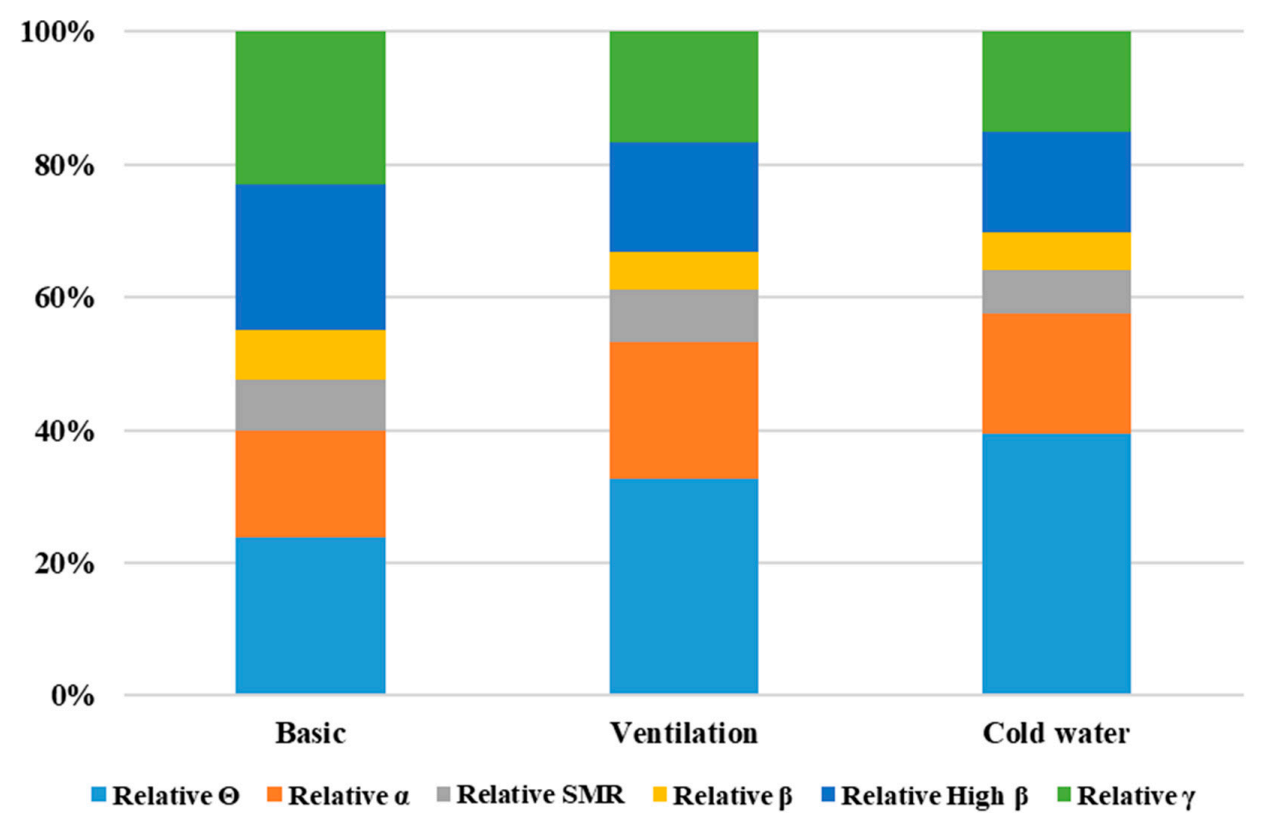

Figure 5. Percentage of electroencephalograms (EEGs) with absolute frequency.

Table 4 shows the activation of the relative $\theta$-wave and relative $\alpha$-wave for each area in the subject's brain when resting using the basic, ventilation, and cold water-cooling seats at an indoor temperature of $27.5^{\circ} \mathrm{C}$ during summer. The difference in the activity of relative $\theta$-wave and $\alpha$-wave at the left and right hemisphere of subject under various resting conditions is shown in Table 4 . The relative $\theta$-wave is more activated when the ventilation and cold water-cooling seats are used. Moreover, the most active brain wave is obtained when using the cold water-cooling seat. Based on this result, it can be concluded 
that a suitable resting environment was provided to the subjects during the break using the cold water-cooling seat. When the subject used the basic seat, the activation of the right hemisphere $\alpha$-wave was prominent, compared to that of the left hemisphere, and the brain waves of the frontal lobes were more active than those in other areas. This indirectly indicates that the basic seat is not suitable for the subject's rest during summer. The use of a ventilation seat showed partial activation in the right hemisphere in some central regions (C3-C4); however, the activation of the left hemisphere in the frontal, temporal, occipital, and some central areas showed stronger activity. Thus, it can be inferred that the subject was in an appropriate state for a comfortable rest, rather than an uncomfortable state. In addition, when the cold water-cooling seat was used, there was a weak activation of the right hemisphere in prefrontal (Fp1-Fp2) and central lobes (C3-C4). However, the use of the cold water-cooling seat is suitable for rest, because activation of the left hemisphere in other areas became stronger.

Table 4. Brain mapping of $\theta$-wave and $\alpha$-wave activities in various seat types.

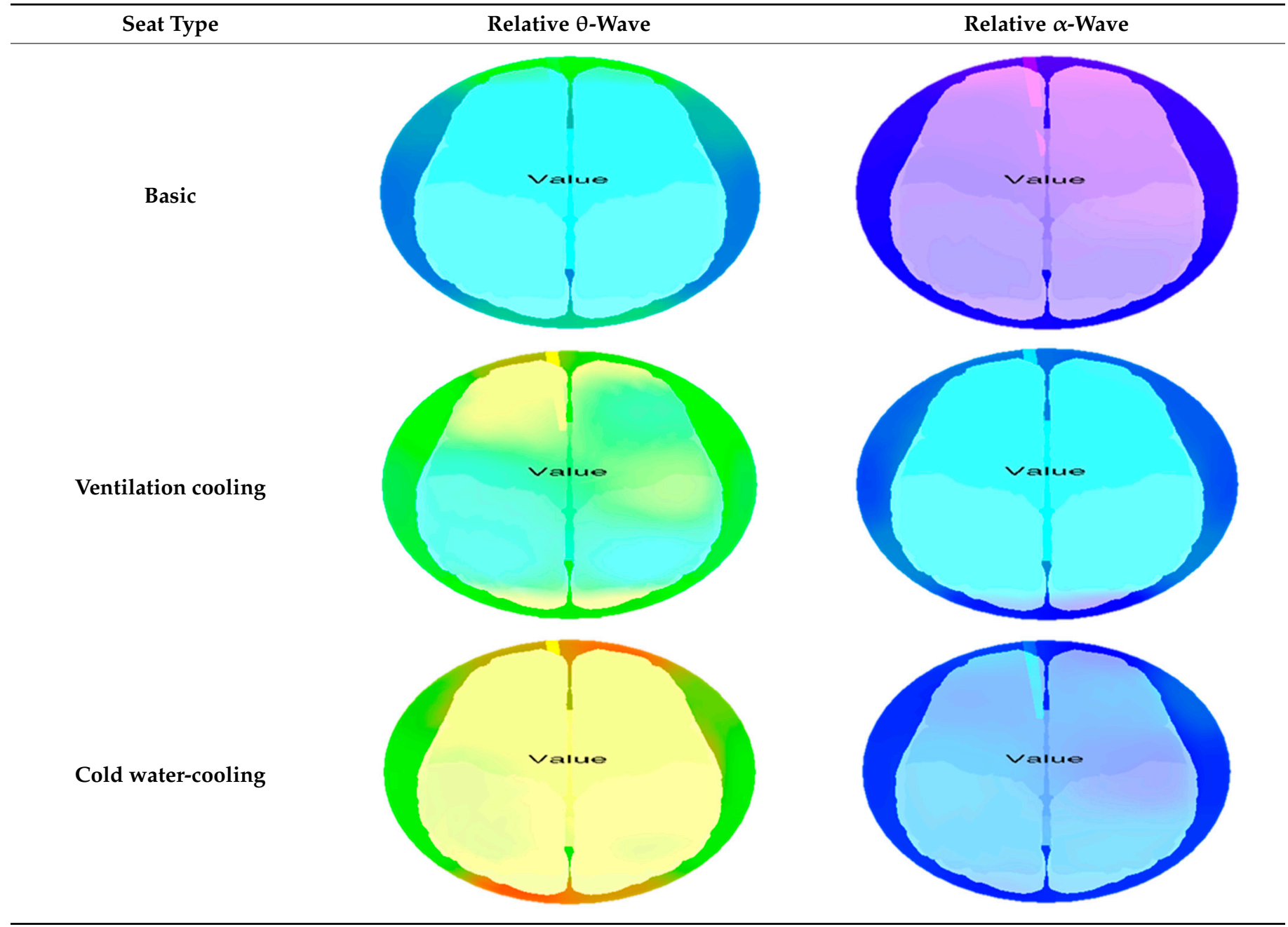

At the indoor temperature of $27.5^{\circ} \mathrm{C}$, the relative $\alpha$-wave was more activated when the ventilation and cold water-cooling seats were used, compared to that when a basic seat was used. As shown in Table 4, the relative $\alpha$-wave was more active when the cold water-cooling seat was used. Therefore, an appropriate rest environment was provided to the subject in this case. When using the basic seat, the activity of the relative $\alpha$-wave, which indicates a stable physical and psychological state, was lower than that for other seat types. Thus, a physical and psychologically stable environment was not created, compared to the cases of using other types of seat. In contrast, when the ventilation seat was used, 
the relative $\alpha$-wave activity was higher than that of the basic seat. In particular, the right hemisphere was more activated in the occipital (O1-O2) and frontal lobes (F7-F8). In the case of using the cold water-cooling seat, which presented the highest relative $\alpha$-wave, the strongest right hemisphere activation occurred in the temporal lobe (T7-T8). This means that it is a stable and comfortable condition, and it provides the highest comfort level, without feeling unpleasant emotions such as anxiety, anger, and depression.

Figure 6 shows the topographical distribution of the average power density of each frequency band during rest when the basic, ventilation, and cold water-cooling seats at the temperature of $27.5^{\circ} \mathrm{C}$ were used. It can be checked the comparison of several brain wave's change at the frontal, parietal, temporal, and occipital lobes of the left and right hemisphere during resting using various seats, as shown in Figure 6. The $\theta$-wave, which is activated during rest, is most active in all areas of the subject's brain. Particularly, when the cold water-cooling seat was used, the activation of the $\theta$-wave increased by $65.7 \%$ and $20.1 \%$, respectively, compared to that when the basic and ventilation seats were used. In general, the SMR and $\beta$-waves, which are activated when focusing on an activity, such as learning or performing serious work, are deactivated in all areas of the left and right hemispheres. This indicates that the subject was resting in a stable and comfortable environment. In addition, when the ventilation and cold water-cooling seats were used, the high $\beta$-wave, which is usually present under tension, and the $\gamma$-wave, which is present in an excited state by recognizing a momentary problem, decreased by $26.6 \%, 32.4 \%$, and $28.4 \%, 35.9 \%$, respectively, compared to those of the basic seat. This indirectly indicates that the use of the ventilation and cold water-cooling seats relieved the subject's tension, compared to the use of the basic seat. The $\alpha$-wave showed similar values at the occipital lobe zone for all the seat types used. However, for the ventilation seat, the $\alpha$-wave was improved by $31.4 \%$ and $15.1 \%$ on average, compared to that when using the basic and cold water-cooling seats, respectively. Generally, the $\alpha$-wave is a relatively relaxed EEG, and is particularly prominent when the eyes are closed. Although no significant difference in the activation of brain waves between the left and right hemispheres was observed when the basic seat was used, when the ventilation and cold water-cooling seats were used, the left hemisphere showed more activation of brain waves in most areas than the right hemisphere. The activation of the left hemisphere indicates that the subject was not in an anxious state due to tension or discomfort, and thus a comfortable rest environment suitable for rest was provided. In this study, the use of a ventilation and cold water-cooling seats provided a more stable resting environment for the subject than the use of the basic seat.

Figure 7 shows the improvement of biosignals according to seat type, compared to the basic seat, when the subject rests using the ventilation and cold water-cooling seats at $27.5^{\circ} \mathrm{C}$ as the indoor temperature condition during summer. LF/HF, which indicates the degree of balance of the autonomic nervous system, is known to decrease, owing to the reduction of activity in the sympathetic nerve during sleep and the increased activity of the parasympathetic nerve. Compared to the use of the basic seat, LF/HF decreased by $1.02 \%$ and $0.85 \%$ when the ventilation and cold water-cooling seats were used, respectively. The BPM decreased by $1.44 \%$ and $2.59 \%$ using the ventilation and cold water-cooling seats, respectively, compared to that using the basic seat. The decrease in the subject's BPM indicates a reduction in the contractile strength of the heart. Thus, it could be predicted that the subject's body temperature decreased when the ventilated and cold water-cooling seats were used, compared to the basic seat. In a comprehensive analysis, the use of a cold water-cooling seat is considered to provide the most pleasant environment for the rest in indoor conditions. 


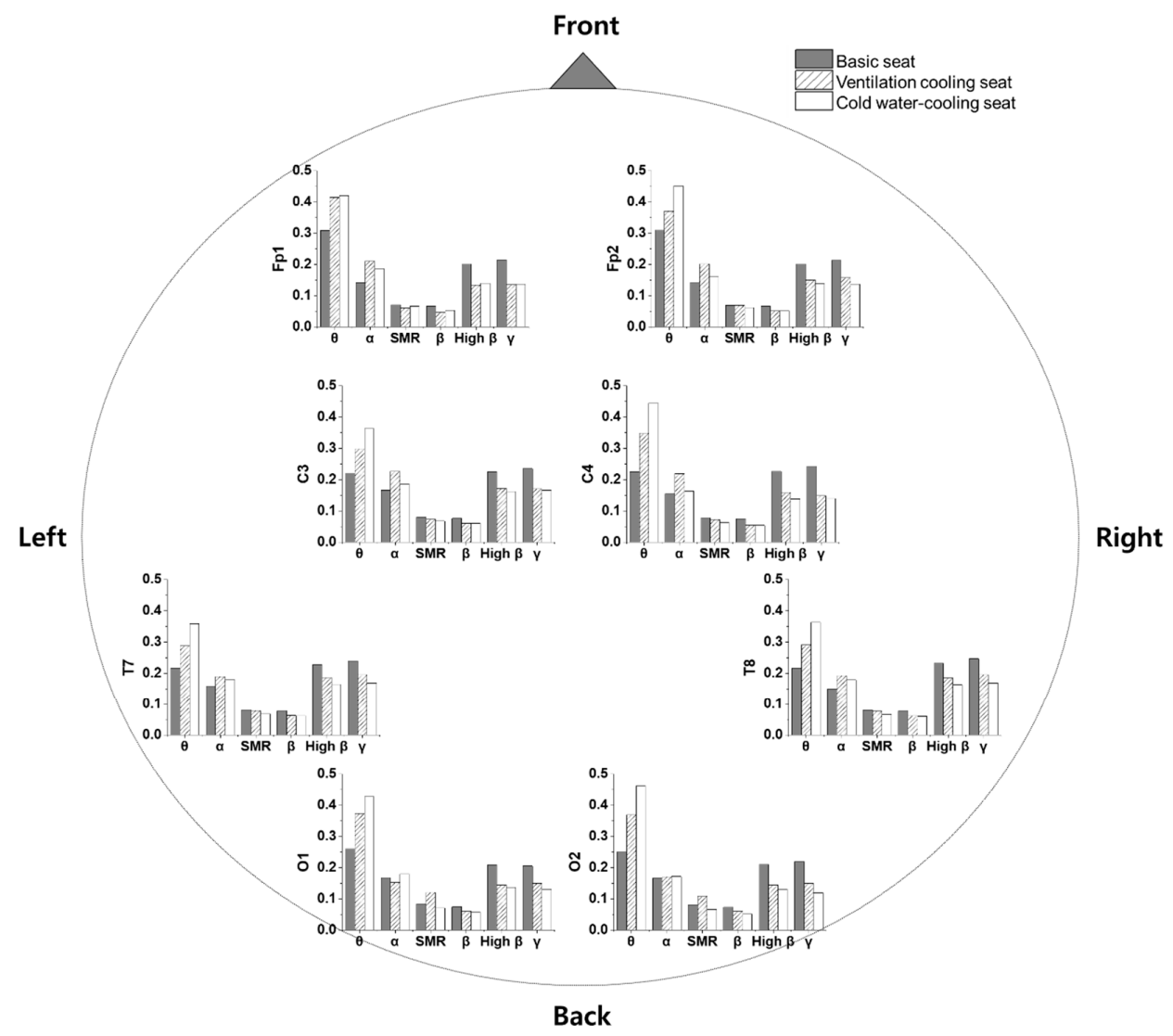

Figure 6. Topographical distribution of average power density in each frequency band on the head for various seat types.

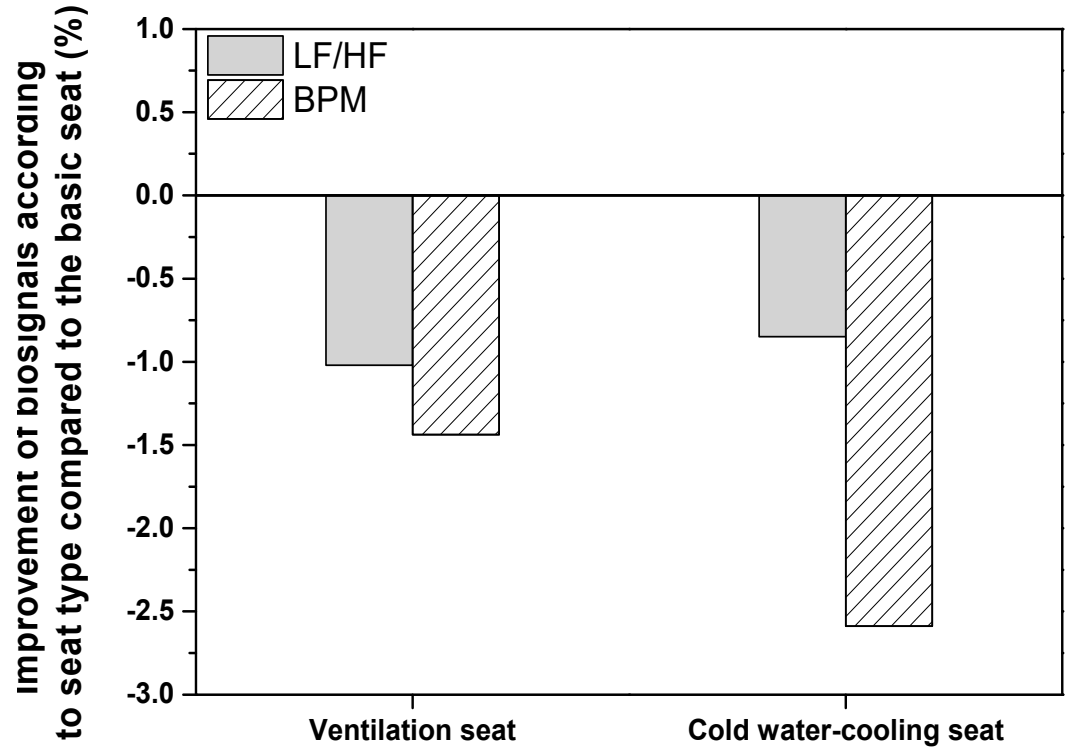

Figure 7. Improvement of biosignals according to seat type, compared to the basic seat.

\subsection{Analysis of Subjective Questionnaires Survyes in the Cooling Condition}

Figure 8 shows a comparison of the TSV, CSV, and CLV after rest using the basic, ventilation, and cold water-cooling seats at a temperature of $27.5^{\circ} \mathrm{C}$ as the indoor temperature condition during summer. As a result of the TSV for the basic seat, $50 \%$ voted the neutral areas which are "warm" or "not cool," and the remaining 50\% voted for "warm," "hot," and "feel hot." However, when using the ventilation seat, $50 \%$ of the subjects chose neutral, 
as in the case of the basic seat, and $33.3 \%$ and $16.7 \%$ voted "cool" and "warm," respectively. When using the cold water-cooling seat, $71 \%$ of the subjects answered "cool," and the other $29 \%$ answered in a neutral area. According to the analysis of the CSV, when the basic, ventilation, and cold water-cooling seats were used, the response rate for the comfort index 2 indicating satisfaction was the same for all three conditions. However, when ventilation and cold water-cooling seats were used, the comfort index was higher than 0 (neutral), and the average comfort level increased by $5.8 \%$ and $13.9 \%$, respectively, compared to the basic seat. Among the three cases, when the subject was resting using the cold water-cooling seat, all subjects responded with a comfort index of 0 or a little higher, thus it was the most satisfactory condition regarding thermal comfort. This means that the use of the ventilation and cold water-cooling seats provided a comfortable environment to the subject for rest in the indoor space during summer.

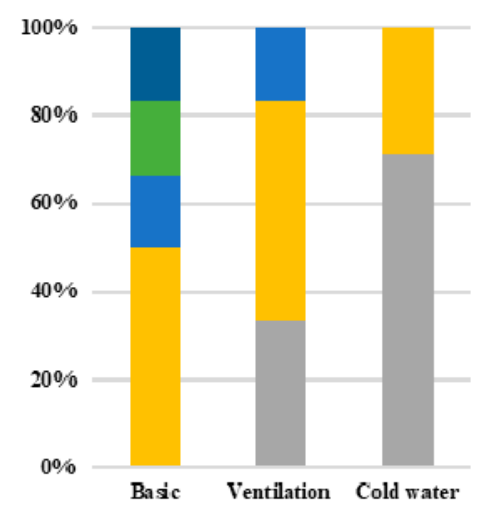

(a) Percentage of TSV

$\square-3 \square-2 \square-1 \backsim 0 \backsim 1 \backsim 2 \backsim 3$

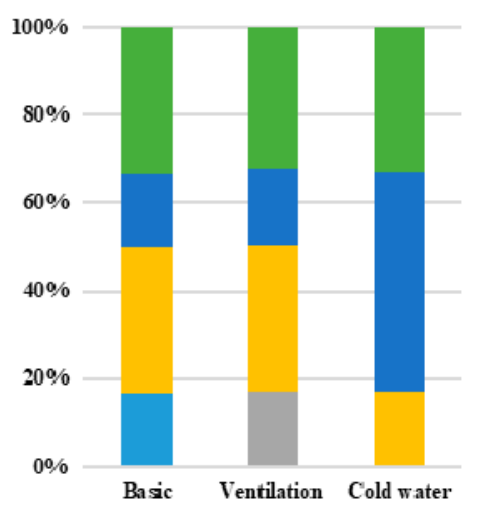

(b) Percentage of CSV

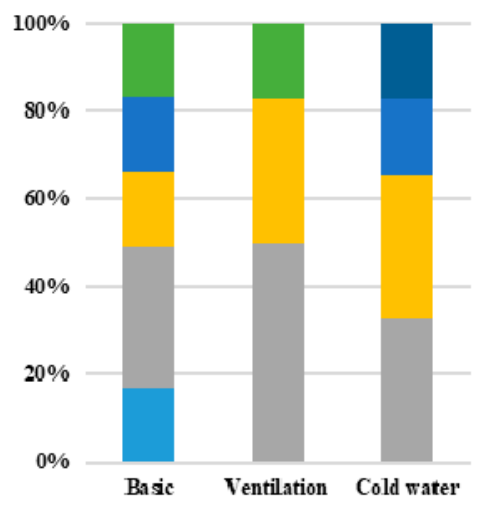

(c) Percentage of CLV

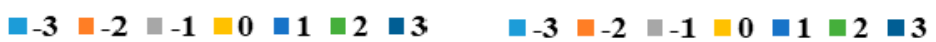

Figure 8. Comparison of subjective survey results in cooling condition.

As a result of the analysis of CLV, for the basic seat, the subjects responded with a minimum attention index of -3 to a maximum of 2; however, the percentage that responded with 0 or less was approximately $67.1 \%$, indicating that the concentration of the subject decreased. However, compared to the basic seat, when the ventilated and cold watercooling seats were used, the attention concentration index improved by $4.6 \%$ and $32.3 \%$, respectively, providing favorable conditions for improving the subject's concentration. As a result of a comprehensive analysis of the results obtained in this study, it is considered that the use of the ventilation and cold water-cooling seats provided a pleasant environment to the subject and increased concentration, compared to the basic seat at an indoor temperature of $27.5^{\circ} \mathrm{C}$. Comparing the three options of this study, the cold water-cooling seat provided the highest concentration and the most comfortable condition for rest, according to the results of the subjective questionnaire.

\section{Conclusions}

In this study, the EEG and cardiac activity status of the human body were analyzed according to various types of seats for indoor rest during summer, and the thermal comfort was evaluated through a subjective survey. As shown in Figures 4 and 5, the $\delta$-wave $(39 \%)$ and $\theta$-wave $(30 \%)$ were most activated when the cold water-cooling and ventilation seats were used, respectively. The results of the cardiac activity analysis showed that the parasympathetic nerve activity increased when the ventilation and cold water-cooling seats were used, compared to that using the basic seat, thus it was concluded that unpleasant feelings, such as anger, anxiety, and fear, were not generated. It was also inferred that the subject's body temperature using the ventilation and cold water-cooling seats decreased as the HR decreased, compared to that using the basic seat. In addition, when analyzing the results of the subjective questionnaires (TSV, CSV, and CLV), the use of the ventilation and 
cold water-cooling seats improved the satisfaction of the subjects for resting, compared to the use of the basic seat.

Compared to the use of the basic seat, LF/HF decreased by $1.02 \%$ and $8.85 \%$, and BPM decreased by $1.44 \%$ and $2.59 \%$, when the ventilation and cold water-cooling seats were used, respectively, as shown in Figure 7. When the cold water-cooling seat was used, $71 \%$ of the subjects indicated they were cool on TSV, which was better than the result for basic and ventilation seats. According to the results of the pleasant sensitivity survey, the average thermal comfort using ventilation and cold water-cooling seats increased by $5.8 \%$ and $13.9 \%$, and the concentration index increased by $4.6 \%$ and $32.3 \%$, respectively, compared to that of the basic seat. Comparing the three options in this study, the cold water-cooling seat provided the highest concentration and the most comfortable condition for resting, according to the subjective questionnaire. Thus, this study can help provide an effective rest environment during learning, driving, and work.

Author Contributions: Conceptualization: M.L. and Y.S.; methodology: M.L. and H.C.; validation: H.C. and M.L.; formal analysis: Y.S.; investigation: Y.S. and M.L.; resources: H.C.; writing-original draft preparation: Y.S.; writing—review and editing: M.L. and H.C.; visualization: Y.S.; supervision: H.C. All authors have read and agree to the published version of the manuscript.

Funding: This study was supported by research fund (team research project) from Chosun University, 2020.

Informed Consent Statement: Informed consent was obtained from all subjects involved in the study.

Data Availability Statement: Data is contained within the article.

Conflicts of Interest: The authors declare no conflict of interest.

\section{References}

1. Hellhammer, D.H.; Wust, S.; Kudielka, B.M. Salivary cortisol as a biomarker in stress research. Psychoneuroendocrinology 2009, 34, 163-171. [CrossRef] [PubMed]

2. Southwick, S.M.; Vythilingam, M.; Charney, D.S. The psychobiology of depression and resilience to stress: Implications for prevention and treatment. Annu. Rev. Clin. Psychol. 2005, 1, 255-291. [CrossRef] [PubMed]

3. Choi, K.M. Corticosteroid therapy for adrenal insufficiency. J. Assoc. Fam. Med. 2003, 24, 1.

4. Byeon, Y.H.; Kwak, K.C. Pre-configured deep convolutional neural networks with various time-frequency representations for biometrics from ECG signals. Appl. Sci. 2019, 9, 4810. [CrossRef]

5. Liu, W.; Fang, X.; Chen, Q.; Li, Y.; Li, T. Reliability analysis of an integrated device of ECG, PPG and pressure pulse wave for cardiovascular disease. Microelectron. Reliab. 2018, 87, 183-187. [CrossRef]

6. Lee, J.; Kim, J.; Shin, M. Correlation Analysis between Electrocardiography (ECG) and Photoplethysmogram (PPG) Data for Driver's Drowsiness Detection Using Noise Replacement Method. Procedia Comput. Sci. 2017, 116, 421-426. [CrossRef]

7. Hong, S.B.; Jung, K.Y. Basic electrophysiology of the electroencephalography. J Korean Neurol. Assoc. 2003, $21,225$.

8. Choi, Y.; Kim, M.; Chun, C. Measurement of occupants' stress based on electroencephalograms (EEG) in twelve combined environments. Build. Environ. 2015, 88, 65-72. [CrossRef]

9. Zhang, F.; Haddad, S.; Nakisa, B.; Rastgoo, M.N.; Candido, C.; Tjondronegoro, D.; de Dear, R. The effects of higher temperature setpoints during summer on office workers' cognitive load and thermal comfort. Build. Environ. 2017, 123, 176-188. [CrossRef]

10. Veselý, M.; Zeiler, W. Personalized conditioning and its impact on thermal comfort and energy performance-A review. Renew Sustain. Energ. Rev. 2014, 34, 401-408. [CrossRef]

11. Pallubinsky, H.; Schellen, L.; Rieswijk, T.A.; Breukel, C.M.G.A.M.; Kingma, B.R.M.; van Marken Lichtenbelt, W.D. Local cooling in a warm environment. Energy Build. 2016, 113, 15-22. [CrossRef]

12. Wang, L.; Tian, Y.; Kim, J.; Yin, H. The key local segments of human body for personalized heating and cooling. J. Therm. Biol. 2019, 81, 118-127. [CrossRef] [PubMed]

13. Lan, L.; Qian, X.L.; Lian, Z.W.; Lin, Y.B. Local body cooling to improve sleep quality and thermal comfort in a hot environment. Indoor Air 2018, 28, 135-145. [CrossRef]

14. Xian, X.; Lan, L.; Xiong, J. Effect of Local Cooling on Thermal Comfort of People in a Sleeping Posture. Procedia Eng. 2017, 205, 3277-3284

15. Veselý, M.; Molenaar, P.; Vos, M.; Li, R.; Zeiler, W. Personalized heating-Comparison of heaters and control modes. Build. Environ. 2017, 112, 223-232. [CrossRef]

16. Zhu, M.; Liu, W.; Wargocki, P. Changes in EEG signals during the cognitive activity at varying air temperature and relative humidity. J. Exp. Sci. Environ. Epidemiol. 2020, 30, 285-298. [CrossRef] 
17. Shan, X.; Yang, E.-H.; Zhou, J.; Chang, V.W.C. Human-building interaction under various indoor temperatures through neuralsignal electroencephalogram (EEG) methods. Build. Environ. 2018, 129, 46-53. [CrossRef]

18. Shan, X.; Yang, E.-H. Supervised machine learning of thermal comfort under different indoor temperatures using EEG measurements. Energy Build. 2020, 225, 110305. [CrossRef]

19. Chang, P.F.; Arendt-Nielsen, L.; Chen, A.C. Comparative cerebral responses to non-painful warm vs. cold stimuli in man: EEG power spectra and coherence. Int. J. Psychophysiol. 2005, 55, 73-83. [CrossRef]

20. Chang, P.F.; Arendt-Nielsen, L.; Chen, A.C.N. Dynamic changes and spatial correlation of EEG activities during cold pressor test in man. Res. Bull. 2002, 57, 667-675. [CrossRef]

21. Shao, S.; Shen, K.; Yu, K.; Wilder-Smith, E.P.; Li, X. Frequency-domain EEG source analysis for acute tonic cold pain perception Clin. Neurophysiol. 2012, 123, 2042-2049. [CrossRef]

22. Shin, Y.; Ham, J.; Cho, H. Investigation on thermal comfort using driver's bio-signals depend on vehicle cabin and vent exit air temperature. J. Mech. Sci. Technol. 2019, 33, 3585-3596. [CrossRef]

23. Diaz-Piedra, C.; Sebastian, M.V.; Di Stasi, L.L. EEG Theta Power Activity Reflects Workload among Army Combat Drivers: An Experimental Study. Brain Sci. 2020, 10, 199. [CrossRef] [PubMed]

24. Yang, L.; Guan, W.; Ma, R.; Li, X. Comparison among driving state prediction models for car-following condition based on EEG and driving features. Accid. Anal. Prev. 2019, 133, 105296. [CrossRef] [PubMed]

25. Jiao, Y.; Deng, Y.; Luo, Y.; Lu, B.-L. Driver sleepiness detection from EEG and EOG signals using GAN and LSTM networks. Neurocomputing 2020, 408, 100-111. [CrossRef]

26. Jing, D.; Liu, D.; Zhang, S.; Guo, Z. Fatigue driving detection method based on EEG analysis in low-voltage and hypoxia plateau environment. Int. J. Transp. Sci. Tech. 2020, 9, 366-376. [CrossRef]

27. Shin, Y.; Im, G.; Yu, K.; Cho, H. Experimental study on the change in driver's physiological signals in automobile HVAC system under Full load condition. Appl. Therm. Eng. 2017, 112, 1213-1222. [CrossRef]

28. Long, S.; Zang, W.; Guo, S.; Lu, J.; Yao, D. A Study on the effect of modulating the quality of sleep by brainwave music. Int. J. Psychophysiol. 2018, 131, S113. [CrossRef]

29. Lan, L.; Pan, L.; Lian, Z.; Huang, H.; Lin, Y. Experimental study on thermal comfort of sleeping people at different air temperatures. Build. Environ. 2014, 73, 24-31. [CrossRef]

30. Barry, R.J.; De Blasio, F.M. EEG differences between eyes-closed and eyes-open resting remain in healthy ageing. Biol. Psychol. 2017, 129, 293-304. [CrossRef]

31. Massar, S.A.; Kenemans, J.L.; Schutter, D.J. Resting-state EEG theta activity and risk learning: Sensitivity to reward or punishment? Int. J. Psychophysiol. 2014, 91, 172-177. [CrossRef] [PubMed]

32. Pitchford, B.; Arnell, K.M. Resting EEG in alpha and beta bands predicts individual differences in attentional breadth. Conscious Cogn. 2019, 75, 102803. [CrossRef] [PubMed]

33. Joshi, S.S.; Lesser, T.J.; Olsen, J.W.; O'Hara, B.F. The importance of temperature and thermoregulation for optimal human sleep. Energy Build. 2016, 131, 153-157. [CrossRef]

34. Zhu, Y.S.; Ouyang, Q.; Shen, H.G.; Zhu, Y.X. Field study on the objective evaluation of sleep quality and sleeping thermal environment in summer. Energy Build. 2016, 133, 843-852. [CrossRef] 